\title{
O MONITORAMENTO E AVALIAÇÃO DA META 4 DO PLANO NACIONAL DE EDUCAÇÃO 2014-2024: contribuições para o debate
}

\author{
Roberval Angelo Furtado \\ Vera Lucia Gomes \\ Rita de Fátima da Silva Rosas de Castro
}

Resumo

O Plano Nacional de Educação (PNE), instituído pela Lei n. 13.005, de 25 de junho de 2014, constitui-se em importante instrumento balizador das políticas educacionais no país para o decênio 2014-2024. O presente artigo trata do monitoramento da Meta 4 considerando o Relatório do $3^{\circ}$ Ciclo de Monitoramento do PNE, disponibilizado pelo Instituto Nacional de Estudos e Pesquisas Estatísticas Anísio Teixeira (INEP), assim como informações relevantes à temática em pauta. São abordadas as questões referentes à elaboração do PNE e as instâncias responsáveis pelo processo de monitoramento e avaliação, ao contexto das metas contidas no documento e, em especial à Meta 4 e seus indicadores, aos marcos legais e conceituais da Educação Especial que, associados aos dados obtidos no que concerne ao acesso às classes comuns, às matrículas nas classes exclusivas e ao atendimento educacional especializado, por etapa de ensino, por regiões do país, contextualizam essa oferta de ensino no país. Neste artigo também são discutidos os aspectos quantitativos do monitoramento ao tempo em que suscitam-se reflexões acerca dos aspectos qualitativos, compondo as contribuições para o debate acerca da inclusão no conjunto da educação nacional, considerando os anseios da sociedade contemporânea.

Palavras-chave: plano nacional de educação (2014-2024); monitoramento; educação especial; educação inclusiva; meta 4.

\section{TITLE IN ENGLISH: THE MONITORING AND EVALUATION OF MARK 4 OF THE NATIONAL EDUCATION PLAN 2014-2024: contributions to the debate}

\begin{abstract}
The National Education Plan (PNE), instituted by Law no. 13.005, June 25, 2014, constitutes an important guiding instrument for country educational policies, for the 2014-2024 decade.This article deals with the Mark 4 monitoring, considering the 3rd PNE Monitoring Cycle Report and the relevant official information to this topic, made available by the National Institute of Statistical Studies and Research Anísio Teixeira (INEP). Are addressed, the preparation issues of the PNE, the monitoring and evaluation process responsible instances, the context of the marks contained in the document and, in particular, Mark 4 and its indicators, the legal and conceptual marks of Special Education that, associated with the obtained data, with regard to access to common classes, registration in exclusive classes and specialized educational assistance, by stage of education, by country regions, contextualize this country teaching offer. In this article are discussed the monitoring quantitative aspects and refleted, at the same time, the qualitative aspects, compound the debate contributions about the set of national education inclusion, considering the desires of contemporary society.
\end{abstract}

Keywords: national education plan (2014-2024); monitoring; special education; inclusive education; mark 4. 
DOI: $10.12957 /$ teias.2022.60928

\section{EL SEGUIMIENTO E EVALUACIÓN DE LA META 4 DEL PLAN NACIONAL DE EDUCACIÓN 2024-2024: \\ contribuciones al debate}

Resumen

El Plan Nacional de Educación (PNE), establecido por la Ley n. 13.005, del 25 de junio de 2014, constituye un importante instrumento para orientar las políticas educativas del país para la década 2014-2024. Este paper trata del seguimiento de la Meta 4 considerando el Informe del 3er ciclo de seguimiento del PNE como información oficial relacionada con la temática en el país, disponible en el Instituto Nacional de Estudios e Investigaciones Estadísticas Anísio Teixeira (INEP). Temas relacionados con la elaboración del PNE y los órganos responsables del proceso de seguimiento y evaluación, el contexto de las metas contenidas en el documento y, en particular, la Meta 4 y sus indicadores, los marcos legales y conceptuales de Educación Especial asociados a los datos. obtenidos en cuanto a acceso a clases comunes, matrícula en clases exclusivas y servicios educativos especializados, por etapa de educación, por regiones del país. Se discuten aspectos cuantitativos del seguimiento al mismo tiempo que plantean reflexiones sobre aspectos cualitativos, componiendo aportes al debate sobre la inclusión en el conjunto de la educación nacional y en las preocupaciones de la sociedad contemporánea.

Palabras clave: plan nacional de educación (2014-2024); vigilancia; educación especial; educación inclusiva; objetivo 4.

\section{INTRODUÇÃO}

Nas últimas décadas, inúmeros avanços ocorreram na educação nacional, principalmente se considerarmos os marcos legais e investimentos técnicos e financeiros efetivados pelos governos das três esferas administrativas, os quais ampliaram e promoveram direitos aos cidadãos e, até hoje, buscam viabilizar a qualidade e a equidade na oferta dos serviços educacionais num país continental como o Brasil, notadamente marcado pela diversidade e pluralidade da composição da sua população e das especificidades locais e regionais.

Nesse contexto, destacamos a Constituição Federal (BRASIL, 1988), que assegurou a educação como direito social e consagrou em seus dispositivos, seja na sua versão original ou por meio de emendas posteriores, questões importantes, como a ampliação da idade escolar obrigatória na educação básica, os fundos de manutenção e valorização dos profissionais da educação, a inclusão e os planos de educação como instrumentos de planejamento do Estado.

A partir das premissas legais, temos a inclusão das pessoas com deficiência nas escolas comuns e, consequentemente, a necessidade de adequação dos espaços escolares quanto à acessibilidade, formação de professores, metodologias, oferecimentos de recursos e serviços e, também, o Atendimento Educacional Especializado (AEE) para o desenvolvimento das potencialidades desses sujeitos. Assim são promovidas as políticas públicas para o acesso e a permanência dos estudantes e o fortalecimento das redes públicas de ensino, por meio de investimentos na formação inicial e continuada de professores e demais profissionais da educação e infraestrutura escolar.

Com o objetivo de atender aos marcos legais existentes e às necessidades advindas da sociedade, o Plano Nacional de Educação, aprovado pela Lei n. 13.005, de 25 de junho de 2014 (BRASIL, 2014a), apresentou dispositivos ratificando a inclusão das pessoas com deficiência nas escolas comuns, tendo a Meta 4 e suas respectivas estratégias como base das ações educacionais para todos os entes federativos. 
Assim, diante das conquistas logradas por meio da legislação para a garantia dos direitos aos cidadãos em matéria educacional, este artigo apresenta considerações sobre o processo de elaboração e implementação da Lei do PNE 2014-2024 e a análise da Meta 4 contida no Relatório do $3^{\circ}$ Ciclo de Monitoramento das Metas do Plano Nacional de Educação - 2020 (BRASIL, 2020), produzido pelo Instituto Nacional de Estudos e Pesquisas Estatísticas Anísio Teixeira (INEP), com o objetivo de contribuir com o debate junto a todos aqueles que estudam e militam por uma educação de qualidade, equânime e inclusiva.

Dessa forma, entende-se a inclusão educacional como aquela em que todos estejam inseridos no mesmo contexto escolar e recebam recursos, serviços e Atendimento Educacional Especializado para complementar e suplementar sua aprendizagem, visando à garantia de "condições apropriadas de atendimento às peculiaridades individuais, de forma que todos possam usufruir das oportunidades existentes (ARANHA, 2001, p. 2).

\section{CONSIDERAÇÕES SOBRE O PLANO NACIONAL DE EDUCAÇÃO 2014-2014}

O Plano Nacional de Educação (PNE 2014-2024) é fruto do esforço e da mobilização dos diversos setores da área educacional e representantes da sociedade civil, por meio das conferências municipais, intermunicipais e estaduais de educação no ano de 2009, as quais antecederam a Conferência Nacional de Educação de 2010 (CONAE/2010), realizada sob a coordenação do Fórum Nacional de Educação, com abordagem de temas estruturantes do setor.

A partir desse movimento coordenado pelo Poder Executivo Federal, o texto do projeto de lei para o então novo PNE foi encaminhado ao Congresso Nacional no final do ano de 2010. Cabe destacar que a tramitação dessa matéria percorreu mais de três anos e meio, considerando as audiências públicas, reuniões, debates e a pressão social à medida que se discutia ou ressoava alguma alteração no texto da norma, principalmente na meta referente à inclusão, Meta 4, e na relativa ao financiamento, Meta 20.

Com a aprovação no Congresso Nacional, o PNE foi sancionado sem vetos por meio da Lei n. 13.005, de 25 de junho de 2014, contendo 14 artigos e um anexo com as 20 metas e as 254 estratégias que abrangem o conjunto da educação nacional, ou seja, todos os níveis, etapas e modalidades de ensino. Para melhor entendermos a organização das metas do PNE, recorremos ao material Planejando a Próxima Década - Conhecendo as 20 metas do Plano Nacional de Educação, elaborado pela extinta Secretaria de Articulação com os Sistemas de Ensino, do Ministério da Educação (SASE/MEC), que assim apresenta:

Há metas estruturantes para a garantia do direito à educação básica com qualidade, que dizem respeito ao acesso, à universalização da alfabetização e à ampliação da escolaridade e das oportunidades educacionais. [...] Um segundo grupo de metas diz respeito especificamente à redução das desigualdades e à valorização da diversidade, caminhos imprescindíveis para a equidade. [...] Um terceiro bloco de metas trata da valorização dos profissionais da educação, considerada estratégica para que as metas anteriores sejam atingidas. [...] Um quarto grupo de metas refere-se ao ensino superior, que, em geral, é de responsabilidade dos governos federal e estaduais [...] (BRASIL, 2014b, p. 12).

Ademais, no corpo da lei do PNE, destacam-se os dispositivos que determinam aos entes federativos a implementação de medidas para que o plano se concretize, dentre os quais destacamos: 
Art. $5^{\circ}$ A execução do PNE e o cumprimento de suas metas serão objeto de monitoramento contínuo e de avaliações periódicas, realizados pelas seguintes instâncias: I - Ministério da Educação - MEC; II - Comissão de Educação da Câmara dos Deputados e Comissão de Educação, Cultura e Esporte do Senado Federal; III - Conselho Nacional de Educação - CNE; IV - Fórum Nacional de Educação. $\ 1^{\circ}$ Compete, ainda, às instâncias referidas no caput: I - divulgar os resultados do monitoramento e das avaliações nos respectivos sítios institucionais da internet; II - analisar e propor políticas públicas para assegurar a implementação das estratégias e o cumprimento das metas; III - analisar e propor a revisão do percentual de investimento público em educação (BRASIL, 2014a).

A partir dessas orientações, os estados, o Distrito Federal e os municípios passaram a elaborar seus respectivos planos, inclusive com apoio do MEC, que disponibilizou uma rede de assistência técnica e formação para atender às equipes locais. Desse esforço colaborativo, obtevese praticamente a totalidade dos entes federativos com planos aprovados em lei, na busca por alinhar o planejamento das ações educacionais no país.

Nessa guisa, corrobora o pensamento de Azevedo, pois o plano se constitui numa "[...] expressão do planejamento, ferramenta usada pelas sociedades objetivando o alcance de metas estabelecidas para sua organização e desenvolvimento, que nas políticas públicas guiam a ação governamental" (AZEVEDO, 2014, p. 266). Dessa forma, a sociedade passa a balizar e a fundamentar as proposições nessa área, com o devido acompanhamento, também dos conselhos e órgãos de controle, como o Ministério Público e os Tribunais de Contas de todas as esferas administrativas.

No que concerne "à redução das desigualdades e à valorização da diversidade, caminhos imprescindíveis para a equidade", propostas do PNE, um dos objetivos foi possibilitar o acesso à educação para todos os cidadãos à margem dessa importante política da sociedade, tornando inclusivos os espaços escolares, as redes e os sistemas de ensino. Nesse sentido, tomamos como recorte para o debate em pauta neste ensaio a inclusão das pessoas com deficiência, transtornos globais do desenvolvimento e altas habilidades ou superdotação na escola comum, tendo como fonte de consulta o resultado constante no Relatório do $3^{\circ}$ ciclo de monitoramento das metas do Plano Nacional de Educação (PNE) - 2020, elaborado pelo Instituto Nacional de Estudos e Pesquisas Educacionais Anísio Teixeira (Inep), referente à Meta 4, Educação Especial.

\section{REVISITANDO MARCOS HISTÓRICOS, LEGAIS E CONCEITUAIS DA EDUCAÇÃO ESPECIAL}

Ao longo da história, as pessoas com deficiência foram marginalizadas, excluídas e discriminadas, integrando os grupos minoritários que não tinham direitos sociais respeitados. A partir das lutas, embates e discussões da sociedade civil sobre o direito ao acesso à educação, esse cenário foi se modificando, principalmente com a busca pela universalização da educação básica contida nos documentos internacionais 'Declaração Mundial sobre Educação para Todos: satisfação das necessidades básicas de aprendizagem' (UNESCO, 1990) e 'Declaração de Salamanca e linhas de ação sobre as necessidades educativas especiais' (UNESCO, 1994), que conclamavam aos países participantes, um compromisso efetivo para:

[...] superar as disparidades educacionais deve ser assumido. Os grupos excluídos - os pobres; os meninos e meninas de rua ou trabalhadores; as populações das 
periferias urbanas e zonas rurais; os nômades e os trabalhadores migrantes; os povos indígenas; as minorias étnicas, raciais e linguísticas; os refugiados; os deslocados pela guerra; e os povos submetidos a um regime de ocupação - não devem sofrer qualquer tipo de discriminação no acesso às oportunidades educacionais. As necessidades básicas de aprendizagem das pessoas portadoras ${ }^{1}$ de deficiências requerem atenção especial. É preciso tomar medidas que garantam a igualdade de acesso à educação aos portadores de todo e qualquer tipo de deficiência, como parte integrante do sistema educativo (UNESCO, 1994, p. 3).

Nessa conjuntura, dados estatísticos mostraram que 70\% das pessoas eram analfabetas nos países em desenvolvimento (UNESCO, 1990). Essa informação promoveu discussões sobre as diversas formas de exclusão nos espaços escolares, os meios para erradicá-las, bem como a reorganização das escolas para que se tornassem inclusivas. A partir da década de 1990, o Brasil, como signatário da 'Declaração Mundial sobre Educação para Todos: satisfação das necessidades básicas de aprendizagem' (UNESCO, 1990), implementou políticas educacionais decorrentes do Plano Decenal de Educação para Todos (1993), visando "uma base política para a sociedade construir uma nova escola [...]" para desenvolver um "[...] conjunto de competências básicas cognitivas e sociais para todos, crianças, jovens e adultos" (BRASIL, 1993, p. 14).

No que se refere à legislação educacional, a Lei de Diretrizes e Bases da Educação n. 9.394/96 apresenta um capítulo específico para a educação especial (Capítulo V) que, dentre outros dispositivos, conceitua essa modalidade de ensino como aquela "[...] oferecida preferencialmente na rede regular de ensino, para educandos com deficiência, transtornos globais do desenvolvimento e altas habilidades ou superdotação" (BRASIL, 1996, Art. 58).

$\mathrm{O}$ atendimento educacional das pessoas com deficiência era realizado por instituições filantrópicas, de forma assistencialista, as quais recebiam repasse financeiro do poder público. Essa oferta era caracterizada como educação especial, acontecia de forma substitutiva ao ensino comum, com organização, currículos e práticas pedagógicas diferenciadas, e era disponibilizada em espaços separados, denominados classes e escolas especiais (MAZZOTTA, 2011).

A partir de 2001, políticas educacionais com o foco na inclusão foram implantadas para promover o acesso e, também, disponibilizar o Atendimento Educacional Especializado, os serviços e recursos necessários para a permanência e o desenvolvimento dos estudantes, preferencialmente em escolas comuns (BRASIL, 2001).

$\mathrm{Na}$ esteira desse movimento e, ainda, influenciado pela globalização e pelo discurso da inclusão educacional, o Brasil começou a reorganizar as políticas educacionais e os sistemas de ensino para que se tornassem inclusivos, respeitando os direitos humanos e as características individuais. Assim, o "Governo Federal opta pela matrícula dessa população em salas comuns de escolas públicas, acompanhado (ou não) de um atendimento educacional especializado, prioritariamente na forma de salas de recursos multifuncionais" (KASSAR, 2011, p. 72).

De forma tênue e gradativa, a partir de 2001, a inclusão educacional foi acontecendo nas escolas públicas (GARCIA, 2016), impulsionada, a partir de 2008, pela instituição da Política Nacional de Educação Especial na Perspectiva da Educação Inclusiva (PNEEI) para garantir a:

Transversalidade da educação especial desde a educação infantil até a educação superior; atendimento educacional especializado; continuidade da escolarização

\footnotetext{
1 Em 2010, o termo "pessoa portadora de deficiência" foi substituído por "pessoa com deficiência" por meio da Portaria n. 2344, de 3 de novembro de 2010, da Secretaria dos Direitos Humanos da Presidência da República.
} 
nos níveis mais elevados do ensino; formação de professores para o atendimento educacional especializado e demais profissionais da educação para a inclusão escolar; participação da família e da comunidade; acessibilidade urbanística, arquitetônica, nos mobiliários e equipamentos, nos transportes, na comunicação e informação; e articulação intersetorial na implementação das políticas públicas (BRASIL, 2008).

A partir da elaboração da PNEEI e dos decretos, resoluções, programas e políticas educacionais implementados no Brasil em decorrência dessa política, o acesso ao atendimento educacional das pessoas com deficiência, transtornos globais do desenvolvimento e altas habilidades ou superdotação, avançou consideravelmente. Segundo Garcia (2016, p. 45):

Apreendemos esse documento como uma estratégia política de produzir um novo consenso articulado, no plano específico, em torno de ideias como o direito à educação dos estudantes da educação especial, a escola regular e o atendimento educacional especializado como forma de atender ao direito à educação, a necessidade de reconhecer a diversidade e as diferenças humanas, a importância dos recursos de acessibilidade.

Outro instrumento legal que agrega dispositivos visando ao aprimoramento da oferta da educação inclusiva é o Plano Nacional de Educação (PNE 2014-2024), que em sua Meta 4 expressa as lutas e discussões advindas da sociedade civil pela garantia do direito à educação, respeito às características individuais e acessibilidade ao prever a universalização do acesso à educação básica e ao AEE. O PNE assevera que a oferta dessa modalidade deve ser "preferencialmente na rede regular de ensino, com a garantia de sistema educacional inclusivo, de salas de recursos multifuncionais, classes, escolas ou serviços especializados, públicos ou conveniados" (BRASIL, 2014a, p. 55), premissas fortemente marcadas na PNEEI de 2008.

A meta em referência é constituída por dezenove estratégias que abordam a universalização do atendimento escolar; o atendimento educacional especializado a todos os estudantes que integram esse público; a implantação de salas de recursos multifuncionais; a formação continuada dos professores para o AEE; a educação bilíngue; a acessibilidade nas escolas públicas; o financiamento pelo Fundo de Manutenção e Desenvolvimento da Educação Básica e de Valorização dos Profissionais da Educação (FUNDEB); dentre outras questões relacionadas à temática.

\section{O MONITORAMENTO DA META 4 DO PNE (2014-2024)}

O monitoramento contínuo e as avaliações periódicas do PNE estão resguardados na letra da lei, inclusive determinando as instâncias responsáveis por esse processo. De acordo com o $₫ 2^{\circ}$ do art. $5^{\circ}$ da lei em tela, o INEP, órgão do Poder Executivo vinculado ao Ministério da Educação, a cada dois anos, "[...] publicará estudos para aferir a evolução no cumprimento das metas estabelecidas [...], com informações organizadas por ente federado e consolidadas em âmbito nacional" (BRASIL, 2014a).

Assim, há que se considerar que os dados apresentados pelo INEP revelam a análise técnica e quantitativa de cada uma das metas, detalhada por indicadores, para subsidiar as instâncias responsáveis por essa ação. Por se tratar de documento público, toda a sociedade pode, ainda, se beneficiar e utilizar essas informações para o devido acompanhamento, estudos e pesquisas. 
Nessas circunstâncias, convém refletir sobre o monitoramento e a avaliação do PNE, compreendendo a necessidade e intencionalidade desse processo imbricado, cujo resultado, geralmente, deve reverberar nas políticas educacionais a serem implementadas no país, servindo como base para a tomada de decisões, proposição de medidas saneadoras para as metas e estratégias que não obtiveram o alcance esperado no tempo analisado. Conforme assevera JANUZZI (2014, p. 32), o monitoramento:

[...] constitui um processo sistemático e contínuo de acompanhamento de uma política, programa ou projeto, baseado em um conjunto restrito - mas significativo e periódico - de informações, que permite uma rápida avaliação situacional e uma identificação de fragilidades na execução, com o objetivo de subsidiar a intervenção oportuna e a correção tempestiva para o atingimento de seus resultados e impactos.

Seguindo essa lógica e considerando a importância de se estabelecer um processo de monitoramento e avaliação dos planos de educação que atenda aos contextos e necessidades locais, Dourado, Grossi Jr. e Furtado (2016, p. 457) destacam que:

[...] os entes federativos devem ter clareza de que o monitoramento e a avaliação dos planos de educação tornam-se elementos imprescindíveis à tomada de decisões dos gestores públicos, visando a garantir a relação eficiência, eficácia e efetividade do que foi planejado, os possíveis ajustes no percurso, a participação da sociedade e a transparência necessária.

No que se refere especificamente ao monitoramento do PNE (2014-2024), o INEP produziu os documentos Plano Nacional de Educação - PNE 2014-2024: Linha de Base, Relatório do $1^{\circ}$ Ciclo de Monitoramento das metas do PNE: Biênio 2014-2016, Relatório do $2^{\circ}$ Ciclo de Monitoramento das Metas do Plano Nacional de Educação - 2018 e Relatório do $3^{\circ}$ Ciclo de Monitoramento das Metas do Plano Nacional de Educação - 2020, em cumprimento aos preceitos legais e com o objetivo de subsidiar o processo em pauta.

No contexto desse monitoramento, retomamos a Meta 4 com a proposta de:

Universalizar, para a população de 4 (quatro) a 17 (dezessete) anos com deficiência, transtornos globais do desenvolvimento e altas habilidades ou superdotação, o acesso à educação básica e ao atendimento educacional especializado, preferencialmente na rede regular de ensino, com a garantia de sistema educacional inclusivo, de salas de recursos multifuncionais, classes, escolas ou serviços especializados, públicos ou conveniados (BRASIL, 2014a, grifo nosso).

Analisando o histórico da educação especial e inclusiva na área educacional brasileira, a meta mostra-se ousada e impõe inúmeros desafios aos gestores do setor e toda sociedade. Nota-se que o acesso à educação infantil ainda é limitado em muitas regiões do país, o ensino médio apresenta elevadas taxas de evasão e reprovação, altos índices de analfabetismo e analfabetismo funcional e o baixo desempenho dos estudantes aferidos por meio do Índice de Desenvolvimento da Educação Básica (Ideb).

Nessa perspectiva, universalizar a educação é cumprir o direito constitucional que tem como princípio a garantia da igualdade de condições para o acesso e permanência na escola para todos, "sem preconceito de origem, raça, sexo, cor, idade e quaisquer outras formas de 
discriminação" (BRASIL, 1988), para fortalecer a participação e desenvolver a cidadania. Para CURY (2013, p. 202):

[...] o direito à educação se liga, intrinsecamente, à função pública do Estado na medida em que só ele pode estender universalmente a escola para todos e assim atender o conjunto dos cidadãos com imparcialidade de modo a fazer cumprir os grandes objetivos da democracia e da justiça.

A meta em referência pressupõe, ainda, "a garantia de sistema educacional inclusivo", o qual acolherá a população de forma adequada para o desenvolvimento das potencialidades dos estudantes. Assim, faz-se necessário compreender o conceito de sistema, o qual SAVIANI (2008, p. 2015) entende como:

[...] um conjunto de atividades que se cumprem tendo em vista determinada finalidade, o que implica que as referidas atividades são organizadas segundo normas que decorrem dos valores que estão na base da finalidade preconizada. Assim, o sistema implica organização sob normas próprias (o que lhe confere um elevado grau de autonomia) e comuns (isto é, que obrigam a todos os seus integrantes).

Nessa perspectiva, um sistema educacional inclusivo "remete para a ampliação dos direitos e inserção social de grupos historicamente marginalizados" (MICHELS, GARCIA, 2014, p. 164). Para tanto, o PNE destaca como proposta que os sistemas de ensino sejam inclusivos, por meio da consecução das suas metas e estratégias. Tecnicamente, convém pontuar que uma meta é aferida por meio dos seus indicadores e que, no caso específico da Meta 4, temos:

Indicador 4A: Percentual da população de 4 a 17 anos de idade com deficiência que frequenta a escola. Indicador 4B: Percentual de matrículas em classes comuns da educação básica de alunos de 4 a 17 anos de idade com deficiência, TGD e altas habilidades ou superdotação. Indicador 4C: Percentual de matrículas na educacão básica de alunos de 4 a 17 anos de idade com deficiência, TGD, altas habilidades ou superdotação que recebem atendimento educacional especializado (BRASIL, 2020).

Assim, tendo como premissa o diálogo acerca do previsto nos indicadores da Meta 4 do PNE e com base nos documentos oficiais acerca do monitoramento deste importante planejamento da política educacional brasileira, com destaque para o Relatório do $3^{\circ}$ Ciclo de Monitoramento das Metas do Plano Nacional de Educação (PNE) - 2020 e as Sinopses Estatísticas da Educação Básica, produzidos pelo Inep, depreendemos os seguintes dados e análises:

Tabela 1 - Número de matrículas em classes comuns da educação básica de estudantes de 4 a 17 anos de idade com deficiência, TGD e altas habilidades ou superdotação (2013-2019)

\begin{tabular}{c|c|c|c}
\hline \multirow{2}{*}{ Ano } & Total & Classes comuns & Classes exclusivas \\
\hline 2013 & 843.342 & 648.921 & 194.421 \\
\hline 2014 & 886.815 & 698.768 & 188.047 \\
\hline
\end{tabular}


DOI: $10.12957 /$ teias.2022.60928

\begin{tabular}{c|c|c|c}
2015 & 930.683 & 750.983 & 179.700 \\
\hline 2016 & 971.372 & 796.486 & 174.886 \\
\hline 2017 & 1.066 .446 & 896.809 & 169.637 \\
\hline 2018 & 1.181 .276 & 1.014 .661 & 166.615 \\
\hline 2019 & 1.250 .967 & 1.090 .805 & 160.162 \\
\hline
\end{tabular}

Fonte: organizada pelos autores com base na Sinopse Estatística da Educação Básica (BRASIL, 2013, 2014, 2015, 2016, 2017, 2018, 2019a).

A Tabela 1 apresenta o número de matrículas da Educação Especial no conjunto da Educação Básica entre os anos de 2013 a 2019, com aumento de 68\% nas classes comuns, passando de 648.921 matrículas em 2013 para 1.090.805 em 2019. Um dado que ainda chama atenção são as matrículas em "classes exclusivas"," as quais obtiveram decréscimo de 17,62\% no período analisado, no entanto, ainda representam 160.162 estudantes.

Ampliando o escopo dessa análise, o Instituto Brasileiro de Geografia e Estatística (IBGE), comparando dados do Censo 2010, estima que 6,7\% da população apresenta algum tipo de deficiência. Calcula-se, ainda, com base na Pesquisa Nacional por Amostra de Domicílios Contínua (2018), que o Brasil possui 35,5 milhões de crianças com até 12 anos de idade. Desse total, considerando a estimativa do IBGE, temos 2.130 .000 crianças com alguma deficiência e, dessas, 1.250.967 estão matriculadas. Assim, podemos concluir que $41,26 \%$ desse público não tem acesso a nenhum tipo de educação, seja nas escolas comuns ou nas escolas especiais. Se considerarmos que a idade escolar obrigatória compreende dos 4 aos 17 anos e ampliarmos a análise dos dados, esse percentual poderá ser maior.

\footnotetext{
${ }^{2}$ Classes exclusivas referem-se às classes especiais localizadas nas escolas comuns e aquelas das instituições filantrópicas sem fins lucrativos.
} 
Figura 1 - Percentual de matrículas em classes comuns da Educação Básica de estudantes de 4 a 17 anos de idade com deficiência, TGD e altas habilidades ou superdotação, por dependência administrativa (2013-2019)

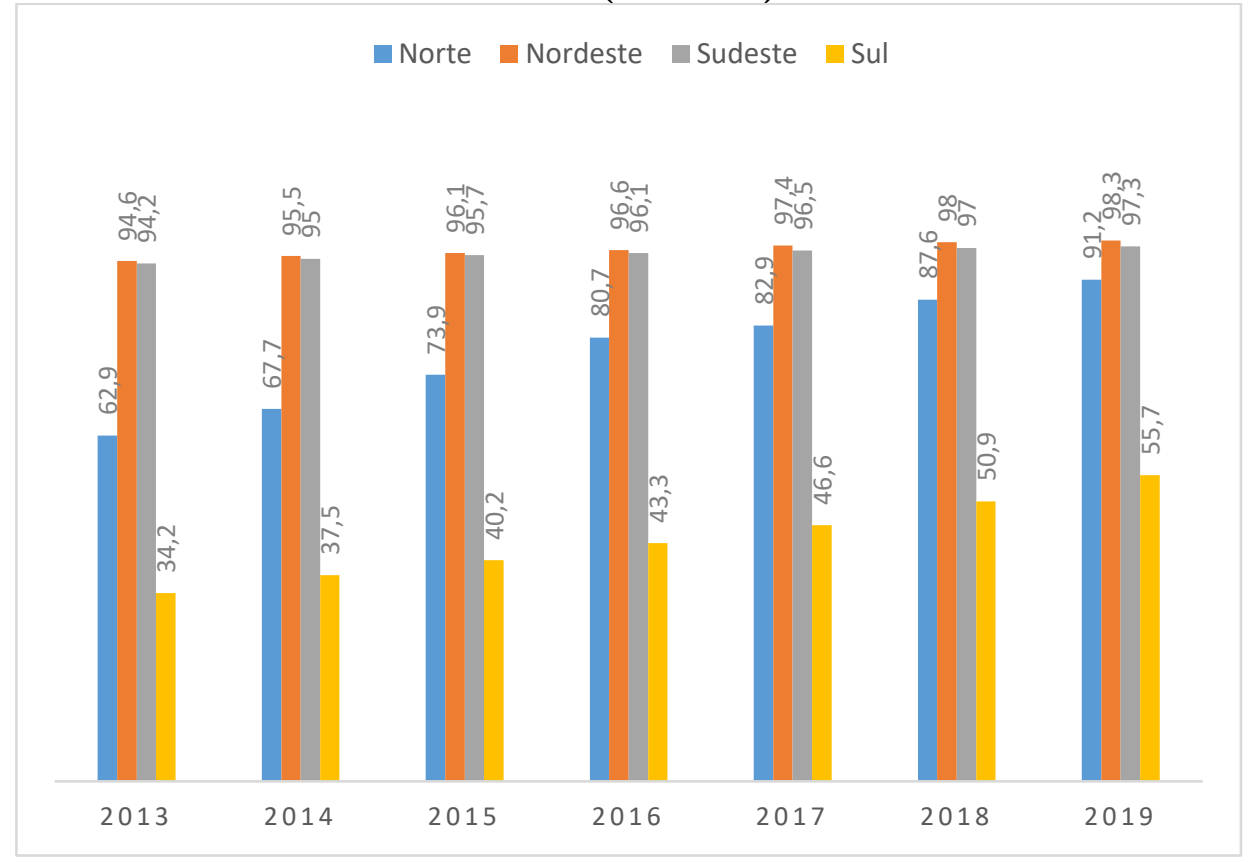

Fonte: Relatório do $3^{\circ}$ Ciclo de Monitoramento das Metas do Plano Nacional de Educação (PNE) - 2020 (BRASIL, 2020)

Nota-se claramente que as redes estaduais e municipais de ensino concentram a maior parte da oferta das matrículas das pessoas público da Educação Especial no período 2013-2019 em classes comuns, com percentuais superiores a 94 pontos.

A análise dos percentuais das escolas da iniciativa privada indica um crescimento de 437\% entre 2013 e 2019; em 2013 eram 39.082 matrículas e, em 2019, 210.245. Esses dados indicam que mesmo com a oferta da educação nas escolas privadas de livre iniciativa e respeitando as normas gerais, o acesso do público da educação especial sempre foi restrito. No entanto, a partir do Estatuto das Pessoas com Deficiência (BRASIL, 2015), a negação da matrícula e a cobrança por atendimentos educacionais complementares tornaram-se passíveis de punição por discriminação, preconceito e violação ao princípio da igualdade de condições para o acesso e permanência na escola, previsto na Constituição Federal (1988), o que tem contribuído para o aumento desse indicador.

É importante sinalizar que o acesso a escola, de todas as crianças e adolescentes, precisa ser entendido de fato como estado de direito e não como concessão. Enquanto entendimento (político, educacional, social) de estado de direito, tem-se uma prática alicerçada no reconhecimento do outro e de suas formas de ser. Esse reconhecimento, por sua vez, sinaliza um avanço no processo civilizador da sociedade que a materializa. Sendo assim, estes elementos colaboram no decorrer de sua consolidação para formas menos arbitrárias de inter-relacionamentos entre pessoas. Ou seja, há um melhor equilíbrio nas relações de poder entre grupos e intragrupos sociais. Todos estes aspectos favorecem uma modificação de paradigma que leva ao estudante com deficiência deixar de ser o ser anômico (sem poder) nas relações estabelecidas no interior da escola, e por conseguinte, ao longo dos tempos, nas relações sociais mais amplas. (SILVA, TAVARES; ARAÚJO, 2006) 
DOI: $10.12957 /$ teias.2022.60928

Tabela 2 - Matrículas da Educação Especial em classe comum por etapas de ensino (2013- 2019)

\begin{tabular}{r|r|r|c}
\hline Ano & Educação Infantil & Ensino Fundamental & Ensino Médio \\
\hline 2013 & 42.982 & 505.505 & 47.356 \\
\hline 2014 & 47.496 & 540.628 & 64.563 \\
\hline 2015 & 51.891 & 576.795 & 74.007 \\
\hline 2017 & 58.772 & 607.232 & 93.231 \\
\hline 2018 & 69.218 & 668.652 & 115.051 \\
\hline 2019 & 91.254 & 741.426 & 124.998 \\
\hline
\end{tabular}

Fonte: organização dos autores com base na Sinopse Estatística da Educação Básica (BRASIL, 2013, 2014, 2015, 2016, 2017, 2018, 2019a).

Os dados acima mostram que o maior quantitativo de matrículas se concentra no ensino fundamental, fato que pode associar-se a inúmeros fatores, dentre eles as políticas de financiamento que remontam à década de 1990, decorrentes do Plano Decenal de Educação para Todos (BRASIL, 1993). Cabe destacar o aumento de $130 \%$ nas matrículas na educação infantil e de $163 \%$ no ensino médio no período analisado. 
Figura 2 - Percentual de matrículas na educação básica de estudantes de 4 a 17 anos de idade com deficiência, transtornos globais do desenvolvimento, altas habilidades ou superdotação que recebem Atendimento Educacional Especializado - Brasil - 2013-2019

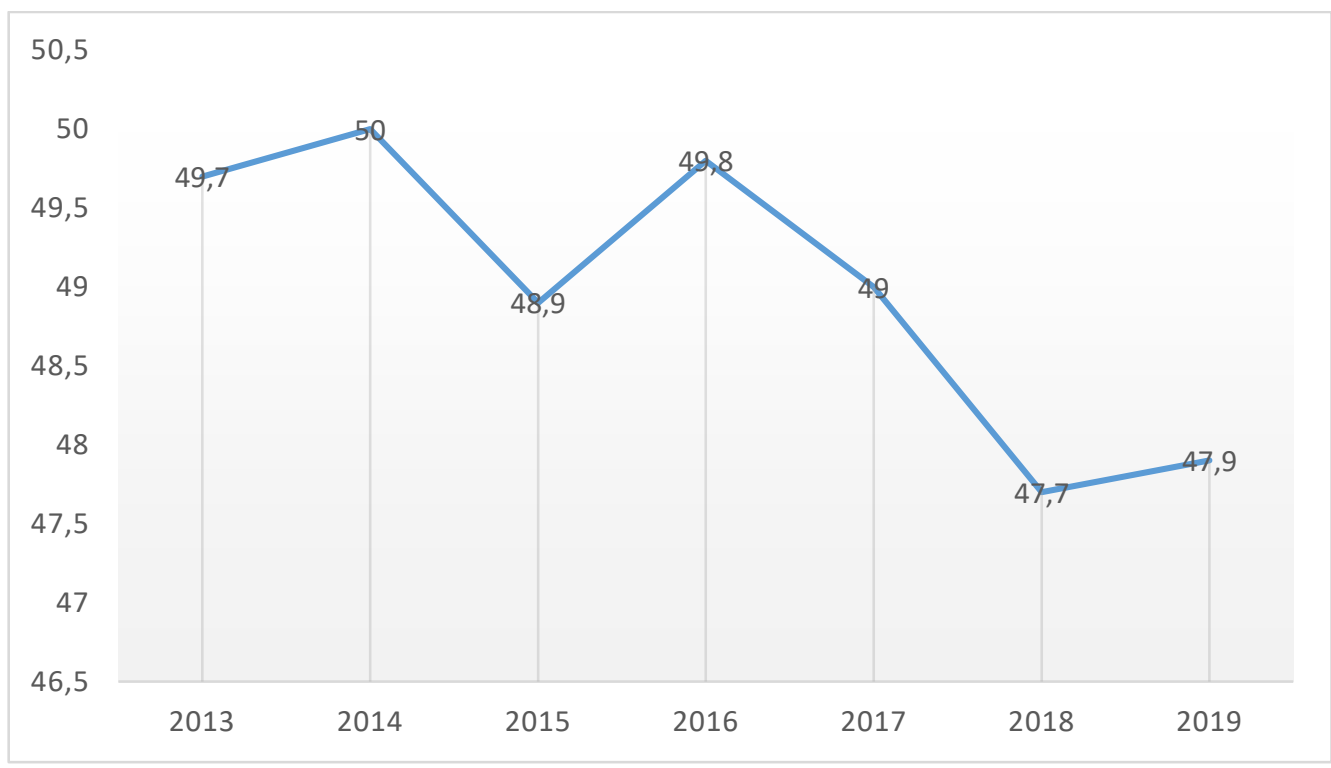

Fonte: Relatório do $3^{\circ}$ Ciclo de Monitoramento das Metas do Plano Nacional de Educação (PNE) - 2020 (BRASIL, 2020)

De acordo com dados do Fundo Nacional de Desenvolvimento da Educação (FNDE), 372.368 matrículas (BRASIL, 2019b) receberam, em 2019, recursos para o AEE por meio do Fundo Nacional de Desenvolvimento da Educação (FUNDEB). Esse atendimento:

[...] é realizado, prioritariamente, na Sala de Recursos Multifuncionais da própria escola ou em outra escola de ensino regular, no turno inverso da escolarização, podendo ser realizado, também, em centro de atendimento educacional especializado público ou privado sem fins lucrativos, conveniado com a Secretaria de Educação" (BRASIL, 2019b).

O quantitativo de matrículas nas escolas comuns, discriminado na Tabela 1, aponta 1.090.805 estudantes em 2019. Percebe-se que somente 34,13 \% desses estudantes recebem o AEE, sinalizando o cumprimento da Meta 4, no que se refere a universalizar o AEE, está muito longe ser efetivado. Outro fator que merece atenção é a queda no percentual de atendimento evidenciada na série histórica 2013-2019. 
Figura 3 - Percentual de matrículas na educação básica de estudantes de 4 a 17 anos de idade com deficiência, transtornos globais do desenvolvimento, altas habilidades ou superdotação que recebem Atendimento Educacional Especializado - grande região (2013-2019)

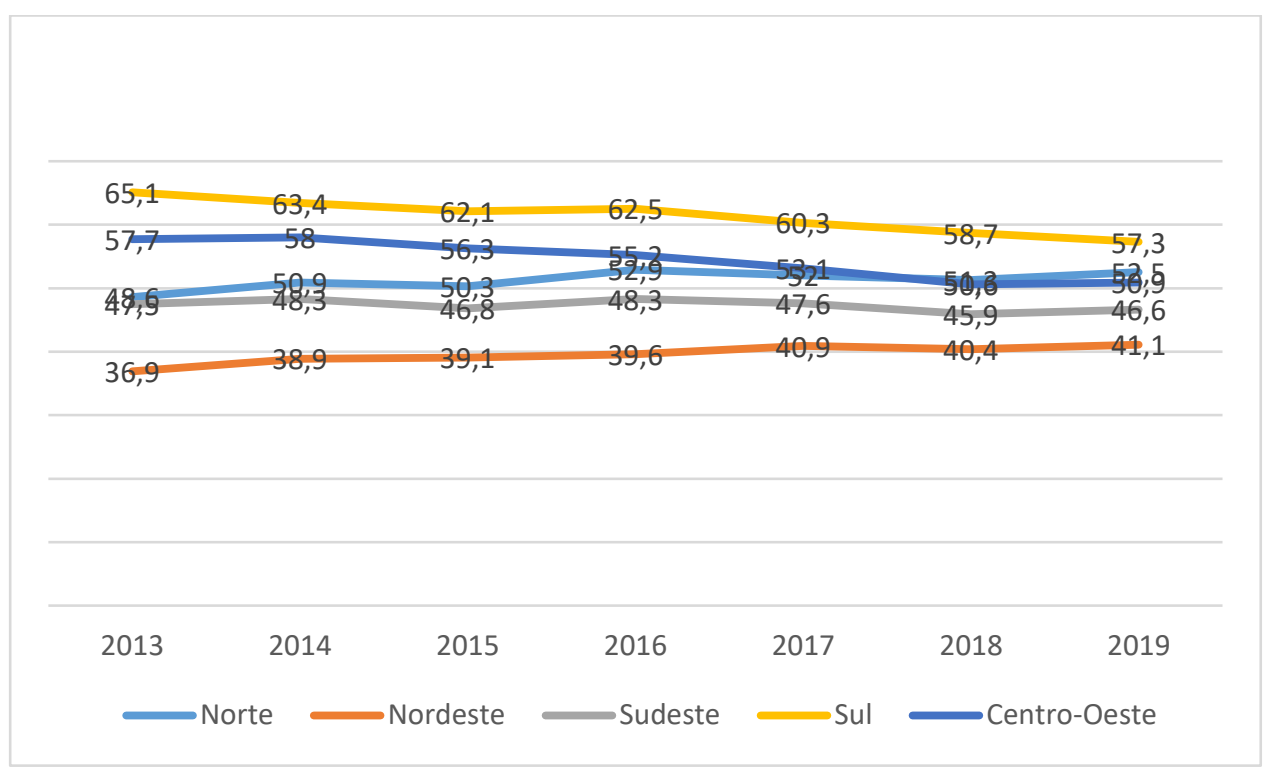

Fonte: Relatório do $3^{\circ}$ Ciclo de Monitoramento das Metas do Plano Nacional de Educação (PNE) - 2020 (BRASIL, 2020)

A análise do percentual de matrículas da população público da Educação Especial que recebe Atendimento Educacional Especializado, apresentado na Figura 3, reforça a existência de desigualdades regionais no país, considerando que regiões que historicamente acumulam perdas e ausências de investimentos nas diversas áreas sociais corroboram baixos indicadores nesta oferta, como o Norte e o Nordeste.

Para além das análises quantitativas que os dados proporcionam, há que se considerar e apontar para o debate as informações que tratam das políticas educacionais dessa área, no que se refere ao planejamento, à gestão, à execução e, principalmente, à qualidade dos serviços prestados e à participação social. Nessa seara, dialogamos sobre qualidade enquanto um conceito polissêmico, o qual não pode ser imposto e sim debatido e pactuado. A qualidade da educação para Dourado e Oliveira (2009, p. 203) é vista como um "[...] conceito histórico, que se altera no tempo e no espaço, ou seja, o alcance do referido conceito vincula-se às demandas e exigências sociais", compreendendo:

[...] dimensões extra e intraescolares e, nessa ótica, devem se considerar os diferentes atores, a dinâmica pedagógica, ou seja, os processos de ensinoaprendizagem, os currículos, as expectativas de aprendizagem, bem como os diferentes fatores extraescolares que interferem direta ou indiretamente nos resultados educativos (DOURADO; OLIVEIRA, 2009, p. 205).

Os autores destacam, ainda, aspectos essenciais para a construção de um sistema educacional com qualidade, dentre eles:

a) as dimensões, intra e extraescolares devem ser consideradas de maneira articulada na efetivação de uma política educacional direcionada à garantia de 
escola de qualidade para todos, em todos os níveis e modalidades; b) a construção de uma escola de qualidade deve considerar a dimensão socioeconômica e cultural, uma vez que o ato educativo escolar se dá em um contexto de posições e disposições no espaço social (de conformidade com o acúmulo de capital econômico, social e cultural dos sujeitos-usuários da escola), de heterogeneidade e pluralidade sociocultural, de problemas sociais que repercutem na escola, tais como fracasso escolar, desvalorização social dos segmentos menos favorecidos, incluindo a autoestima dos alunos etc.; d) o reconhecimento de que a qualidade da escola para todos, entendida como qualidade social, implica garantir a promoção e atualização histórico-cultural, em termos de formação sólida, crítica, ética e solidária, articulada com políticas públicas de inclusão e de resgate social (DOURADO; OLIVEIRA, p. 212).

Vista a partir da compreensão de que a escola é um espaço que contribui com as mudanças nas relações sociais pela produção e disseminação do saber historicamente produzido, a qualidade fica comprometida quando se trata do desequilíbrio no acesso (SAMPAIO; OLIVEIRA, 2015), que é uma das dimensões da desigualdade educacional e necessita ter suas causas e implicações compreendidas para a formulação de políticas públicas educacionais.

Desse modo, as políticas públicas intencionam materializar os direitos garantidos em leis, evidenciando as ações voltadas aos cidadãos que delas estão à margem, inclusive quando se trata da política educacional. Portanto, convém destacarmos que a materialização da Meta 4 do PNE não está somente relacionada à universalização do acesso para a população público da Educação Especial, considerando o quantitativo das matrículas, pois oportunizar somente o acesso não é garantia de que essa população alcance a aprendizagem de acordo com as suas necessidades e especificidades.

\section{CONSIDERAÇÕES FINAIS}

O PNE (2014-2024) se constitui num amplo instrumento de planejamento da educação nacional para o decênio 2014-2024, elaborado a partir do debate ocorrido nas conferências de educação, envolvendo as diversas representações da área. A lei que instituiu o PNE (2014-2024) previu o processo de monitoramento constante e avaliações periódicas com representantes de instituições que atuam na proposição e consecução das políticas educacionais.

A partir dos dados oficiais e, principalmente, os que constam no documento produzido pelo Inep, denominado Relatório do $3^{\circ}$ Ciclo de Monitoramento das Metas do Plano Nacional de Educação - 2020, obtivemos um panorama quantitativo acerca da inclusão das pessoas com deficiência em classes nos sistemas de ensino, conforme preconiza o PNE, assim como a oferta em classes exclusivas e o Atendimento Educacional Especializado, tendo como recorte histórico o período de 2013 a 2019.

Além disso, na análise do Censo Escolar, coletado e divulgado anualmente pelo Inep, notase a ausência dos dados da oferta do Atendimento Educacional Especializado, tanto nas salas de recursos multifuncionais nas escolas comuns de educação básica quanto nos centros de atendimento educacional especializado, já que em muitas situações as instituições conveniadas assumem esse atendimento em detrimento ao papel do Estado.

Assim, a atual conjuntura de governo com cortes nos recursos financeiros para a educação sinaliza uma preocupação quanto à materialização do PNE (2014-2024), especificamente da Meta 4 , pois a política entra em conflito com dispositivos do plano e de outras propostas vinculadas ao 
movimento mundial da educação inclusiva. Além disso, não há como avançar em qualquer proposição sem que haja o devido financiamento.

\section{REFERÊNCIAS}

ARANHA, Maria Salete Fábio. Inclusão social e a municipalização. In: Manzini E.F. (org.) Educação Especial: Temas atuais. Marília. Unesp Publicações,2001. Paradigmas da relação da sociedade com as pessoas com deficiência. Revista do Ministério Público do Trabalho, 2001.

AZEVEDO, Janete Maria Lins de. Plano Nacional de Educação e planejamento. A questão da qualidade da educação básica. Revista Retratos da Escola, Brasília, 2014. Disponível em file:///C:/Users/Vera/Downloads/441-1503-1-PB\%20(1).pdf. Acesso em 23 ago. 2020.

BRASIL. Constituição da República Federativa do Brasil. Diário Oficial da União (DOU), Seção I, p. 1, 5 de outubro de 1988.

BRASIL. Lei n. 9.394, de 20 de dezembro de 1996. Lei de Diretriz̧es e Bases da Educação Nacional. Brasília, DF. 1996.

BRASIL. Conselho Nacional de Educação. Resolução n. 2, de 11 de setembro de 2001, institui as Diretrizes Nacionais para a Educação Especial na Educação Básica. Brasília, DF, 2001.

BRASIL, Ministério da Educação. Secretaria de Educação Especial. Política Nacional de Educação Especial na Perspectiva da Educação Inclusiva. Inclusão: Revista da Educação Especial, Brasília, v.4, n. 1, jan./jun. CIBEC/MEC, 2008.

BRASIL. Ministério da Educação e do Desporto. Plano decenal de educação para todos. Brasília, DF, 1993.

BRASIL. Lei n. 13.005, de 25 de junho de 2014. Aprova o Plano Nacional de Educação - PNE e dá outras providências. Diário Oficial da União, Brasília, DF., 26 jun 2014a. Disponível em: http://www.planalto.gov.br/ccivil 03/ ato2011-2014/2014/lei/113005.htm. Acesso em 30 agosto 2020.

BRASIL. Ministério da Educação. Secretaria de Articulação com os Sistemas de Ensino. Planejando a Próxima Década Conhecendo as 20 Metas do Plano Nacional de Educação. Brasília, DF., 26 jun 2014b. Disponível em: https://observatoriodoconhecimento.org.br/planejando-a-proxima-decada/. Acesso em 30 agosto 2020.

BRASIL. Presidência da República. Lei Brasileira de Inclusão da Pessoa com Deficiência. Lei n. 13.146, de 06 de Julho de 2015. Institui a Lei Brasileira de Inclusão da Pessoa com Deficiência (Estatuto da Pessoa com Deficiência). Brasília, DF. 2015. Disponível: http://www.planalto.gov.br/ccivil 03/ ato2015-2018/2015/lei/113146.htm. Acesso em: 17 mai. 2021.

BRASIL. Instituto Nacional de Estudos e Pesquisas Educacionais Anísio Teixeira. Sinopse Estatística da Educaşão Básica, 2013, 2014, 2015, 2016, 2017, 2018, 2019. Brasília, DF, 2019a. Disponível em: http://inep.gov.br/sinopses-estatisticas-da-educacao-basica. Acesso em: 29 jun. 2020.

BRASIL. Fundo Nacional de Desenvolvimento da Educação, Matrículas da Educação Básica. Brasília, DF. 2019b. Disponível em: https://www.fnde.gov.br/financiamento/fundeb/consultas. Acesso em 11 ago. 2020.

BRASIL. Instituto Nacional de Estudos e Pesquisas Educacionais Anísio Teixeira. Relatório do 30 ciclo de monitoramento das metas do Plano Nacional de Educação - 2020. Brasília, DF 2020. Disponível em: 
http://portal.inep.gov.br/informacao-da-publicacao/-

Lasset publisher/6JYIsGMAMkW1/document/id/6957506. Acesso em: 30 agosto 2020.

CURY, Carlos Roberto Jamil. Sentidos da educação na Constituição Federal de 1988. RBPAE - v. 29, n. 2, p. 195-206, mai/ago. 2013. Disponível em: https://seer.ufrgs.br/rbpae/article/view/43518.pdf. Acesso em: 12 set. 2020.

DOURADO, Luiz Fernandes; GROSSI JUNIOR, Geraldo; FURTADO, Roberval Angelo Monitoramento e Avaliação dos Planos de Educação: Breves Contribuições. Revista Brasileira de Política e Administração da Educação. v. 32, n. 2, p. 449 - 461 mai./ago. 2016. Disponível em: https://seer.ufrgs.br/rbpae/article/view/67198. Acesso em: 12 set. 2020.

DOURADO, Luiz Fernandes; OLIVEIRA, João Ferreira de. A Qualidade a Educação: Perspectivas e Desafios. Cad. Cedes, Campinas vol. 29, n. 78, p. 201-215, maio/ago. 2009. Disponível em: http://www.scielo.br/pdf/ccedes/v29n78/v29n78a04.pdf. Acesso em 21 ago. 2020.

GARCIA, Rosalba Maria Cardoso. Educaşão Especial na Perspectiva Inclusiva: Determinantes Econômicos e Políticos. Disponível. Comunicações Piracicaba v. 23 n. 3 Número Especial p. 726, 2016. Florianópolis. Santa Catarina. Disponível em: file://C:/Users/User/Desktop/doutorado/2018/pesquisas $\% 20$ meta $\% 204 /$ Rosalba.pdf. Acesso em 15 ago. 2020.

JANNUZZI, Paulo de Martino. Avaliação de programas sociais: conceitos e referenciais de quem a realiza. Est. Aval. Educ., São Paulo, v. 25, n. 58, p. 22-42, maio/ago., 2014. Disponível em: http://publicacoes.fcc.org.br/ojs/index.php/eae/article/view/2916/2768. Acesso em: 08 de set. de 2020.

KASSAR, Mônica de Carvalho Magalhães. Educação especial na perspectiva da educação inclusiva: desafios da implantação de uma política nacional. Educar em Revista, Curitiba, Brasil, n. 41, p. 61-79, jul./set. 2011. Editora UFPR. Disponível em: https://www.scielo.br/pdf/er/n41/05.pdf. Acesso em: 13 de abr. 2021.

MAZZOTTA, Marcos José da Silveira. Educação especial no Brasil: história e políticas públicas. 6. ed. São Paulo: Cortez, 2011.

MICHELS, Maria Helena; GARCIA, Rosalba Maria Cardoso. Sistema Educacional Inclusivo: Conceito e Implicações na Política Educacional Brasileira Cad. CEDES vol.34 no.93. Campinas, 2014.

SAMPAIO, Gabriela Thomazinho Clementino; OLIVEIRA, Romualdo Portela de. Dimensões da desigualdade educacional no Brasil. Revista Brasileira de Política e Administração da Educação - v. 31, n. 3, p. $511 \quad-\quad 530 \quad$ set./dez. $2015 . \quad$ Disponível em: http://seer.ufrgs.br/index.php/rbpae/article/view/60121/37016. Acesso em 21 set. 2020.

SAVIANI, Demerval. Desafios da construção de um sistema nacional articulado de educaşão. Trab. Educ. Saúde, v. 6 n. 2, p. 213-231, jul./out.2008.

SILVA, Rita de Fátima da; TAVARES, Maria da Consolação Gomes Cunha Fernandes; ARAÚJO, Paulo Ferreira de. As diferentes percepções das e sobre as pessoas em condição de deficiência. Revista de Psicologia Teoria, Investigação e Prática, v. 11, n. 2, p.2227-42, 2006.

UNESCO. Declaração Mundial sobre Educaşão para Todos: satisfação das necessidades básicas de aprendizagem. Brasília. UNESCO, $1990 . \quad$ Disponível em: http://unesdoc.unesco.org/images/0008/000862/086291por.pdf. Acesso em 20 ago. 2020.

UNESCO. Declaração de Salamanca e linhas de ação sobre a necessidades educativas especiais. Brasília. UNESCO, 1994. Disponível em: http://portal.mec.gov.br/seesp/arquivos/pdf/salamanca.pdf. Acesso em: 20 mar. 2018. 


\section{Informações dos autores}

Roberval Angelo Furtado

Universidade Católica de Brasília

E-mail: robervalfurtado@gmail.com

ORCID: https://orcid.org/0000-0003-0441-3470

Link Lattes: http://lattes.cnpq.br/0278411060061716

Vera Lucia Gomes

Universidade Católica de Brasília

E-mail: vera.lucia@ufms.br

ORCID: https://orcid.org/0000-0002-1902-6652

Link Lattes: http://lattes.cnpq.br/5471472549645629

Rita de Fátima da Silva Rosas de Castro

Universidade Católica de Brasília

E-mail: rita.fatima@ufms.br

ORCID: https://orcid.org/0000-0001-7024-5175

Link Lattes: http://lattes.cnpq.br/4696703886385634 